\title{
Research on teachers' needs when using e-textbooks in teaching
}

\author{
Yen-chen Lin ${ }^{1 *}$, Tzu-Chien Liu ${ }^{2}$ and Kinshuk ${ }^{3}$
}

\author{
* Correspondence: \\ 981407004@cc.ncu.edu.tw \\ ${ }^{1}$ Graduate Institute of Learning and \\ Instruction, National Central \\ University, Jhongli City, Taiwan \\ Full list of author information is \\ available at the end of the article
}

\begin{abstract}
The major purposes of this study were to understand teachers' definitions of e-textbooks, to identify teachers' needs when using e-textbooks and to explore the relationships between teachers' needs of using e-textbooks and teachers' attributes. To achieve these major purposes, an open questionnaire was proposed to experts to obtain their requirements of using e-textbooks. A needs of using e-textbooks perception scale (NUEPS) was then constructed based on teacher interview results, the literature review and the results of the open questionnaire mentioned above. In the formal study, 378 elementary and secondary school teachers were selected to complete NUEPS, and the reliability and validity of the scale were checked. The results indicated that the teachers' needs when using e-textbooks comprised three factors: (1) to support teaching activities (STA); (2) to support reading and presentation (SRP); and (3) to support learning activities and parental interaction (LAPI). Besides, the findings of the study showed that the Taiwanese school teachers' perceptions of using e-textbooks were positive in average. There were no significant differences in terms of gender and age, but there were differences regarding teachers' school level, and application experience in both the STA and SRP sub-dimensions. The results of this study can be used to offer a better understanding of teachers' needs of using e-textbooks, and to help novice teachers' application in e-textbook.
\end{abstract}

Keywords: E-textbook; Mobile learning; Digital book; Educational technology

\section{Introduction}

In this digital age, the usage of e-textbooks in the classroom is becoming increasingly popular (Woody et al. 2010; Shepperd et al. 2008; Tees, 2010). E-textbooks can be seen as e-books that contain educational materials and functions, and which can be used for educational purposes (Landoni \& Diaz, 2003). However, the definition of e-textbooks often changes because the development of technologies and the new application of these technologies in education are progressing at such a rapid rate (Jung \& Lim, 2009). Currently, e-textbooks usually offer various major features which are described as follows. First, e-textbooks can display various digital resources, such as digital texts, photos, animations, simulations, videos, audio and other resources (Chen et al., 2013; Shepperd et al. 2008; Woody et al. 2010). Second, e-textbooks can support learning with some basic text functions such as highlighting, annotating, searching, bookmarking, referring and editing (Chen et al., 2013; Lam et al. 2010; McFall et al. 2006; Woody et al. 2010). These functions make the usage of e-textbooks more convenient. Besides, the contents can be easily

\section{焦 Springer}


updated by publishers, and the functionality allows students to access the latest knowledge at any time and in any place (Brusilovsky et al., 2004). Third, e-textbooks provide students an easy access to Internet resources (such as websites and online quizzes) (Chen et al., 2013; Lam et al. 2010; Nelson \& Webb, 2007; Woody et al. 2010). This feature also enables teachers to easily assign relevant materials to students according to the students' levels (Brusilovsky et al., 2004; Chen et al., 2013; Nelson \& Webb, 2007; Everett, 2009). Finally, e-textbooks allow students to share what they do in their e-books (e.g., annotations and highlight) and what they think (e.g., reports and notes) with other students. This feature can enhance students' collaborative learning or interaction (Chen et al., 2013; Huang et al., 2008 \& Huang et al. 2009; Järvelä et al., 2007; Kodippili, \& Senaratne, 2008; McFall \& Dahm, 2004; McFall et al. 2006; Ravid et al. 2008).

In the past there have been many scholars reporting in-depth research on e-book's functions and features. For example, Chen et al. (2013) have used Delphi method in Beijing for school administrators, teachers, students, parents and researchers, etc. These studies explored the concept of e-textbook in elementary schools, which declared a number of e-textbook in features and functions. In addition, Taizan et al. (2012) compared digital textbooks in Japan and Korea from the viewpoint of functions and effect. The study on e-book offered a great help of understanding in this realm. Some applications in the classroom, such as recent learning innovation in instructional technology, and emerging technologies with instruction (e.g., IRS, classroom management systems, and mobile devices) have become increasingly popular. The combination of the context taught in the class and the use of e-textbook makes the e-textbook possible. The features and functions are better than those in the past. The success of information integration in teaching, teachers play a key role in this new education era (Liu, 2007; literature). Therefore, what teachers' needs regarding the features and functionality of e-textbook have become an interesting issue for the researchers to explore.

\section{Literature review}

\section{The application of e-textbook in learning and teaching activities}

With the development of mobile devices, IRS combining with the learning system increased the diversity of teaching and learning in the application of e-textbook. Many previous studies have demonstrated students' usage of e-textbook (Daniel, \& Woody, 2013; McGowan et al. 2009; McFall et al. 2006; Nicholas et al. 2010; Quan-Haase \& Martin, 2011; Rose, 2011; Rockinson- Szapkiw et al., 2013; Sun et al. 2012; Weisberg 2011). For example, McFall et al. explored university teachers' usage of e-textbooks in reading courses and reported positive responses from teachers. They can assign the students reading assignments and know which part requires more attention as well as who have a correct understanding of the material. Furthermore, it can help teachers classify misunderstandings and designate students to assist their classmates. For their efficiency in teaching, teachers argued that the use of e-textbooks had fully changed their teaching approaches, providing them with a better connection to the students and their learning, and enabling more effective use of class time for teachers who do not like to give lessons using traditional books (McFall et al. 2006). In recent years, not only the trend of using e-textbooks in m-learning has appeared, but also the birth of many opinions on improving students the reading and learning efficiency by using of e-textbooks, has showed up. It provides the students with higher learning desires, 
greater self-motivation, and enhanced learning capacities (Woody et al. 2010; Shepperd et al., 2008; Korat \& Shamir 2008; Luik \& Mikk 2008; De Jong \& Bus 2004; Maynard \& Cheyne 2005). In the classroom, it is the teachers who generally decide whether and how to adopt information technologies (innovative technologies) and often the teachers' attitudes towards technologies determine whether the technologies can elicit the expected effects in the classroom (Hew \& Brush, 2007; Keengwe \& Onchwari, 2008; Liu, 2007; Teo, 2008; Ertmer, 2005). For example, do these functions fit teachers' requirements? What functions do teachers mostly need? Do teachers with different attributes need e-textbooks with different functions? To explore these questions, the following sections firstly review the related literature to explore the possible relationships between teachers' attributes and their perceptions of the use of technology.

However, much of the literature on e-textbooks is from the researchers' perspective, while only a few studies have examined how teachers perceive e-textbooks. Thus far, we have no proper tools available to study teachers' perceptions of e-textbooks. Furthermore, different studies have shown that gender, age, school level, application experience and other background factors may affect users' application of technologies. However, few studies exploring teachers' opinions of their e-textbook needs have been carried out, and thus it is of great significance for both theoretical and teaching practice purposes to construct reliable and valid tools to understand the teachers' perspectives on e-textbooks.

\section{Teachers' attributes and their perceptions of the use of technology}

Previous studies have shown that users with different attributes may hold varied perceptions of the use of technologies (Liu et al. 2010; McGowan et al. 2009; Wang et al., 2009; Uzunboylu \& Ozdamli 2011). It is known that teachers play a critical role in determining whether and how to apply technologies in their classrooms, However, students are usually the ones, rather than the teachers, who have served as the subjects of study in previous relevant research. In this study, we consider the literature on gender, age, school level, and application experience factors.

First, because few studies have explored the relationships between teachers' gender and the use of e-textbooks, several studies related to the effect of students' gender on the usage of e-textbooks are also reviewed here. Some studies have found that male students are more likely to read e-textbooks. For example, Liu and Huang (2008) surveyed the effect of undergraduate students' gender on their reading behaviors and experiences regarding printed materials and electronic media. They found that female students preferred reading printed materials while male students were more satisfied with electronic learning materials. In addition, McGowan et al. (2009) found that male students from universities and graduate schools were more likely to use e-textbooks. However, some other studies (e.g., Wang et al., 2009; Liu et al. 2010) found that males and females have very similar perceptions of or ways of using mobile devices. In addition, there are few studies on gender differences in teachers' perceptions of the use of e-textbooks. In one study that did investigate this issue, Uzunboylu and Ozdamli (2010) found that male teachers' perceptions of mobile technologies were comparatively more positive than those of female teachers; for instance, male teachers were more likely to believe that mobile technology-based learning systems improve the quality of their lessons, teachers can have instant access to materials, the appliances can be utilized as a supplement to 
traditional education, and teacher-student communication can be enhanced by means of m-learning tools.

Second, from the perspective of age, McGowan et al. (2009) indicated that older students showed a stronger preference for e-textbooks than younger students. In one of the studies investigating the determinants of m-learning usage intention which explored how age difference moderates the influence of these determinants on usage intention, the results indicated that age difference moderated the effects of effort expectation and social influence on m-learning use intention (Wang et al., 2009). The teacher group most inclined to apply computer-based technology to teachers' classroom instruction was the middle-aged group in a technology-rich environment (Hung \& Hsu, 2007).

Third, only a limited number of studies on school levels have been performed and are available. So and Swatman (2006) studied primary school teachers in Hong Kong and compared them with teachers in secondary schools. They found that teachers in primary schools were less familiar with the use of technologies in teaching. Hsu (2010) investigated 3,729 teachers from grades 1 through 9 in Taiwan in terms of six aspects, namely (1) information collection and preparation; (2) material producing and troubleshooting; (3) communication and sharing; (4) planning, teaching and evaluation; (5) professional development and self-study; and (6) ethics, health and safety issues, and found that elementary school teachers had a higher level of preference for the use of technologies in teaching compared to teachers in middle or high schools. Teachers at different levels have been found to have varying opinions on the use of technologies in teaching, and this may also be true for the use of e-textbooks in the classroom. According to International Society for Technology in Education (2003), there was no significant differences were found in computer availability between differenct school types (elementary vs. secondary school).

Fourth, regarding teachers' application experience, computer experience has a significant effect on attitudes toward technology (Levine \& Donitsa-Schmidt, 1998; Smith et al. 2000; Woodrow, 1992). There was significant positive correlation between teachers' level of ICT use and their attitudes towards ICT (Al-Zaidiyeen et al. 2010). Teachers' competency in using ICT has also been found to be a strong determinant of their level of technology use in the classroom (Bauer \& Kenton, 2005; Wozney et al., 2006). If teachers have more experience with instructional design, they would be able to conduct better class preparation (Gong et al. 2013). Therefore, teachers' attributes and their perceptions of the use of e-textbooks should be cleared.

\section{Purpose}

On the basis of the literature review, this study aims: (a) to construct a needs scale of using e-textbooks and to test its reliability and validity; (b) to survey teachers' needs when using e-textbooks; and (c) to explore the relationship between teachers' needs and other variables that are related to the teachers' personal characteristics, such as gender, age, school level, and application experience in the classroom.

\section{Methodology}

\section{Participants}

This research involved 415 teachers from 22 elementary and secondary schools in Taiwan as subjects. The teachers were enrolled in a teacher education program that 
was held in three areas in Taiwan. The return rate was $91.1 \%$, with 378 usable questionnaires available for analysis.

\section{Development of NUEPS}

According to the basic aims of this research, a scale was used to determine the teachers' perceptions of their demands for using e-textbooks. Based on the literature review, we identified four stages in the development of the needs of using e-textbooks perception scale (NUEPS). In the first stage, 6 open questions relevant to instruction using e-textbooks in real-life situations were proposed on the basis of the literature review. These questions, which were prepared for five teachers who worked as experts in the field of integrating technologies in elementary or secondary school teaching, involved how teachers should present their materials, and how to act as coaches and facilitators to improve students' learning (see Appendix A). The five teachers are experienced in using e-textbook. Their teaching experience in the application of technology in the classroom is 10 years at average. After the interviews, the teachers' definitions of e-textbooks were evaluated and used in the follow-up study.

In the second stage, on the basis of the opinions of these five educational technology experts and the literature review, 27 items were constructed. For content validation, three elementary school teachers, two secondary school teachers, and one university professor who had experienced using e-textbooks were consulted to assess the quality of each item, confirm their classification in the NUEPS, and suggest necessary item revisions. The five teachers have experienced in the application of technology in the classroom. The professor's experience in integration technology in teaching and research were 13 years. Some experts were invited to help measure the validity of the six questions. A 4-point scale was used. The calculation of this questionnaire content validity index value is 0.96 . In line with CVI value should be 0.8 or more of the requirements (Waltz, et al., 2010). This shows the validity of the questionnaire in this study is fairly good. Lastly, five items were added to the questionnaires as a result of the specialist reviews. Thus, the scale consisted of 32 items. All of the items were measured using a five-point Likert scale, where 5 indicated "strongly agree" and 1 indicated "strongly disagree".

In the third stage, this pilot instrument was administered to 95 teachers to perform the reliability and validity analysis. Data collected from the pilot instrument helped to determine the scale's items, and the average, standard deviation, and the total item correlation of each parameter were calculated. The average item grades were between 3.92 and 4.41, whereas the standard deviation was between 0.84 and 1.02. Analysis results of the item analysis, which was show to determine the discrimination of the items, revealed that the total item correlation was between 0.45 and 0.88 . No items were removed from the original questionnaire. The reliability coefficient of the entire scale was measured as Cronbach's $\alpha=0.98$.

In the fourth stage, the final questionnaire was divided into two parts. The first part, which consisted of questions, focused on the demographic information of the teachers, including their gender, age, length of teaching experience, and school level, among other factors. The second part consisted of the 32 items related to the needs of using e-textbooks. The questionnaires were delivered to the teachers who attended the training program on using technologies in the classroom. Completion of the 
questionnaire was completely voluntary and anonymous. Frequency analysis of the data was used to demonstrate the teachers' distribution in this stage. Coefficients of regression and MANOVA were calculated using SPSS 12.0. A level of 0.5 was established as a priori for determining statistical significance. The whole stage was shown in Figure 1.

\section{Results and Discussion}

In this study, questionnaires were distributed to teachers who applied e-book in learning activities. Teachers enrolling in a free and voluntary program were asked to fill in the questionnaire. Among the participants, 55.30\% were female (169 males and 209 females); the teachers (elementary school teachers: $71.9 \%$, secondary school teachers: $28.1 \%$ ) were from 24 to 58 years old with an average age of 38 . The percentage of participants with experience using e-textbooks in teaching was $68.5 \%$, and those without such experience comprised 31.5\%. Teacher's background varied from subjects (e.g., Chinese languages, English, mathematics and other 10 subjects) to grade level (1 to 9). Besides, sometimes they are required to take turns to teach the different subjects and the target students' grade level. The average of teaching experience is 13.51 years.

\section{Teacher's views on the requirements of e-textbooks}

In the interviews performed during the first stage, the teachers expressed their views regarding their e-textbook requirements:

Teacher 1: "Teachers should choose e-textbooks based on curriculum outlines for use in teaching. E-textbooks should have some functions which echo the curriculum outlines similar to how teachers should teach and consistent with the requirements of the curriculum outline, which are used to prepare lessons following the teaching manuals or guidance, and to provide students with corresponding assignments and quizzes, etc. Thus, in addition to the same contents in traditional textbooks, e-textbooks should provide convenient and more easily integrated multimedia functions".

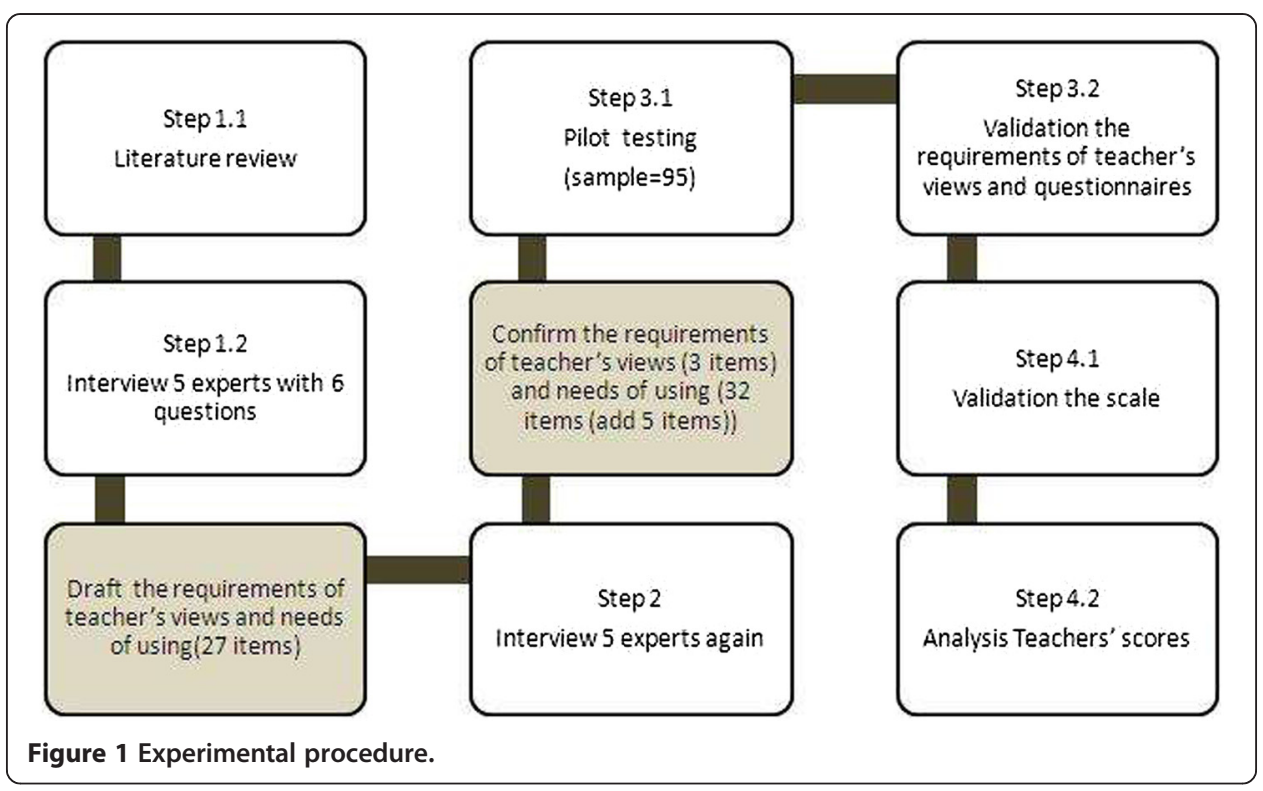


Teacher 2: 'Basic functions included in e-textbooks for students' use should provide no answers for students' assignments, offer supplementary explanations, hyperlinks and favorable settings, while those for teachers' use (a version that differs from the students' version) should have supplementary teaching explanations, such as answers for assignments, assessments and other things, and instructional videos integrated in one place".

Teacher 2: "We still cannot do without approved versions of materials consistent with the textbook review and approval policy. Due to unified assessments and things such as these in approved versions of the materials, such materials fail to meet the students' individual needs. To cope with individual needs, e-textbooks should have additional supplements".

Teacher 3: "The school bought some books once, and these were not reviewed and approved versions of the materials, if you teach using such books, what would parents say? ... We received disapproval from the parents".

Teacher 4: "Why do we trust textbooks? They have definitely been reviewed and have met approval standards. Thus, if we make e-textbooks in Taiwan, then their review and approval are a must. In reality, parents attach great value to such things (textbooks) - review and approval will give parents reassurance regarding their children's use of e-textbooks, but self-prepared ones (teaching materials) are susceptible to the parents' disapproval".

Teacher 5: "We should not only add multimedia and hyperlinks to existing textbooks, but also put in teacher-student interactions and overall support of learning records and assessments".

Taken together, the teachers' views on the requirements of e-textbooks are summarized as follows: (1) use approved e-textbooks; (2) e-textbooks should have not only textbook contents but also digitalized assessments or teaching materials such as assignments and academic records; (3) e-textbooks should have multimedia presentation functions to help the students learn. We distributed these three perceptions and questionnaires to teachers and performed descriptive statistics after retrieving the questionnaire responses. We found high levels of agreement among the teachers for these three items, with values for "agree" and "strongly agree" ranking above $81.1 \%$, and with all the means higher than 4.12(Cronbach's alpha $(\alpha)=0.953$ ) (see Table 1 ). Both the elementary and secondary school teachers surveyed thought that e-textbooks were positively defined as "ones whose compilations follow the teaching objectives, contents, ability indicators and so on in the Grade 1-9 curriculum outlines, that have passed review and approval, and that are equipped with multimedia presentation functions plus digitalized assessments or teaching materials, such as assignments and academic records". This definition requires conformity with the Grade 1-9 curriculum outlines and approvals, which varies from the definitions in the existing literature (Shepperd et al. 2008; McFall et al. 2006). The teacher thought that content and version of e-textbook could be better if these could be accredited or reviewed by the official. The findings in this study are coincident with the claims found in Chen et al. (2013) study. 
Table 1 Teacher's perceptions of their requirements for using e-textbooks $(n=95)$

\begin{tabular}{|c|c|c|c|c|c|c|c|}
\hline Item & $\begin{array}{l}\text { Strongly } \\
\text { disapprove }\end{array}$ & Disapprove & Neutral & Agree & $\begin{array}{l}\text { Strongly } \\
\text { agree }\end{array}$ & Mean & SD \\
\hline $\begin{array}{l}\text { 1. I would choose reviewed and } \\
\text { approved e-textbooks (those } \\
\text { whose compilations follow the } \\
\text { teaching objectives, contents, } \\
\text { ability indicators and so on in } \\
\text { the Grade } 1-9 \text { curriculum outlines). }\end{array}$ & $2.10 \%$ & $5.30 \%$ & $11.60 \%$ & $41.10 \%$ & $40.00 \%$ & 4.12 & .96 \\
\hline $\begin{array}{l}\text { 2. E-textbooks should have not } \\
\text { only textbook contents but also } \\
\text { digitalized assessments or } \\
\text { teaching materials, such as } \\
\text { assignments and study lists. }\end{array}$ & $.00 \%$ & $6.30 \%$ & $7.40 \%$ & $35.80 \%$ & $50.00 \%$ & 4.31 & .86 \\
\hline $\begin{array}{l}\text { 3. I need e-textbooks that have } \\
\text { multimedia presentation functions } \\
\text { to facilitate the students' learning. }\end{array}$ & $1.10 \%$ & $3.20 \%$ & $8.50 \%$ & $38.30 \%$ & $48.90 \%$ & 4.31 & .84 \\
\hline
\end{tabular}

\section{Needs of using e-textbook perception scale (NUEPS)}

Our study provides the first findings on teachers' perceptions of e-textbooks in Taiwan. The data in the scale were generated to determine the teachers' perceptions of their needs when using e-textbooks.

\section{Validity}

In this study, the NUEPS Scale was validated by using factor analysis. Through the method the study can identifying items whose removal would enhance the internal consistency reliability and the scale's factor structure. The results of the Kaiser-Meyer-Olkin (KMO) and Bartlett's Test reveal $\mathrm{p}=0.00$, and the values of the KMO were above 0.90. According to these analysis results, it conclude that the sample data were adequate for factor analysis. Next, principal component analysis was performed on the data to explore the component structure underlying the instrument. The average of the scale items was between 4.06 and 4.47. Besides, the standard deviation was between 0.72 and 0.91 . The analysis results of total item correlations, which were used to determine the discrimination of the items, all items were above 0.40 , ranging from 0.40 to 0.81 . Three factors were found in the teachers' perceptions of the e-textbook scale. The total variance obtained by the three factors was estimated as $63.554 \%$ after the Varimax rotation (in Table 2). Table 2 represents the items included in the factors after the Varimax rotation.

According to the results of the analysis, we have three components. The items' contents, which were obtained from the factors and their appropriateness to the theoretical structure, were taken into consideration in providing titles for these three sub-dimensions: 'Supporting Teaching Activities' (STA, 13 items), 'Supporting features and functions of Reading and Presenting' (SRP, 13 items), and 'Learning Activities and Parent Interaction' (LAPI, 6 items). Pearson correlation of the dimensions was calculated to observe the relationship among the dimension of the scale after factor analysis. It concluded that the interactions among all dimensions were strong, ranging from 0.77 to 0.87 . In this context, upon examining the correlations regarding the total points, the scale measures have the desirable features.

Reliability

The internal consistency reliability of the three scales in NUEPS was determined in the study by calculating the Cronbach's alpha reliability coefficient for the above 
Table 2 NUEPS mean, SD, factor, and reliability results

\begin{tabular}{lllll}
\hline Item and factors & Mean & SD & Factor \\
\hline Factor I: STA Cronbach's alpha (a) $=0.953$ Half-split reliability $=0.932$ & & & \\
I need e-textbooks for classroom teaching, & & & \\
26. To support sharing of bookmarks among students & 4.06 & .84 & .762 \\
25. To support sharing of notes among students & 4.18 & .84 & .739 \\
22. To match with the learning diagnostic systems and to help & 4.36 & .80 & .670 \\
the teachers adjust to teaching & & & \\
18. To support convenient exchange and sharing of teaching & 4.41 & .76 & .637 \\
materials among teachers & & & \\
24. To support sharing of cooperative learning outcomes & 4.36 & .76 & .614 \\
21. To provide digital learning materials for students at any time & 4.39 & .77 & .614 \\
20. To support the analysis of formative assessments after & 4.40 & .76 & .594 \\
performing in-class quizzes & & & \\
23. To match with the implementation of cooperative learning & 4.35 & .74 & .592 \\
16. To have access to a fully classified table of contents provided & 4.15 & .86 & .589 \\
by the textbook publishers & & & \\
14. To obtain cues for reading progress & 4.14 & .82 & .545 \\
17. To have access to an updated version of e-textbook contents & 4.43 & .78 & .516 \\
at any time & & & \\
19. To support the implementation of in-class quizzes & 4.37 & .74 & .515 \\
15. To have access to instruction manuals & 4.27 & .86 & .510 \\
Factor I Total & 4.30 & .64 &
\end{tabular}

Factor II: SRP Cronbach's alpha $(a)=0.947$ Half-split reliability $=0.902$

If I use e-textbooks in teaching, I need:

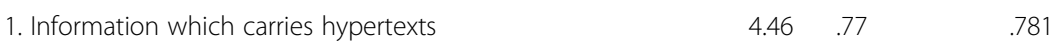

$\begin{array}{llll}\text { 2. Easy previous and next pages to facilitate reading } & 4.46 & .78 & .767\end{array}$

$\begin{array}{llll}\text { 3. Content pages similar to those in printed books to match the } & 4.40 & .81 & .757\end{array}$ students' reading habits

$\begin{array}{llll}\text { 4. Functions to change the size, font, color and other character } & 4.43 & .79 & .714\end{array}$ style features to match the students' reading habits

7. Abundant content to meet my in-class teaching demands $\quad \begin{array}{llll}\text { 7.43 } & .44 & .567\end{array}$

11. Enabled Internet access $\quad 4.33 \quad .89 \quad 552$

$\begin{array}{llll}\text { 13. Function to track the students' reading page } & 4.37 & .75 & .537\end{array}$

$\begin{array}{lllll}\text { 9. Function to edit contents to adjust teaching } & 4.47 & .72 & .526\end{array}$

$\begin{array}{llll}\text { 6. Function to enable hand input } & 4.36 & .78 & .523\end{array}$

10. Access to a compatible format to facilitate the integration $\quad 4.38 \quad .76 \quad 523$ of my use with other digitalized teaching material

5. Bookmark features which can be shared $\quad 4.33 \quad .78$

$\begin{array}{lllll}\text { 8. Function to display on various devices (such as computers, } & 4.45 & .77 & .492\end{array}$ laptops, pocket PCs, tablet PCs, smart phones and other devices)

12. Function to broadcast in wireless networks $\quad 4.29 \quad .85$

Factor II Tota

$4.40 \quad .62$

Factor III: LAPI Cronbach's alpha (a) $=0.915$ Half-split reliability $=0.901$

If I use e-textbooks in teaching, I need a :

31. Function to support the parents' reading and signing of $\quad 4.14 \quad .90$ contact books

32. Function to enable parents to manage and use the accounts

30. Function to enable the students to batch upload electronic $\quad 4.31 \quad .78$ 
Table 2 NUEPS mean, SD, factor, and reliability results (Continued)

\begin{tabular}{|c|c|c|c|c|}
\hline $\begin{array}{l}\text { 29. Function to enable students to perform the assignments in } \\
\text { the e-textbooks after class }\end{array}$ & 4.28 & .83 & & .673 \\
\hline 27. Function to enable student notetaking & 4.37 & .76 & & .586 \\
\hline 28. Function to use the highlight feature in the book & 4.44 & .75 & & .486 \\
\hline Factor III Total & 4.26 & .71 & & \\
\hline Eigenvalues & & 18.630 & 1.413 & 1.322 \\
\hline$\%$ Variance & & 23.198 & 23.139 & 17.216 \\
\hline$\%$ Total variance & & 22.198 & 46.338 & 63.554 \\
\hline
\end{tabular}

sample. The results in Table 2 indicate that the internal consistency reliability ranged from 0.91 to 0.95 for the three NUEPS scales. For the whole scale, the Cronbach's alpha $(\alpha)$ value was 0.98 , and the half-split reliability of the scale was 0.93 . For the 'STA' sub-dimension, the Cronbach's alpha $(\alpha)$ value was 0.95 , with a half-split reliability of 0.93 . For the 'SRP', the Cronbach's alpha $(\alpha)$ value was 0.95 , and the half-split reliability was 0.90. Finally, for the 'LAPI' sub-dimension, the Cronbach's alpha $(\alpha)$ value was 0.92 , and the half-split reliability was 0.90 . Thus, the internal consistency reliability of the measures used in this study can be considered as favorable.

Based on the results of this study, it is suggested that the reliability and validity criteria for the scale were high. The sub-dimension of 'STA' contained statements that described the e-textbooks' application modes, assessment and needs of the implementing remedial learning and studies, which share functional needs among students when teachers are using e-textbooks in teaching. The sub-section of 'SRP' contained statements on features that supported e-textbook reading and the presentation of functions and operations, a function to enable network access, a teaching-presenting function in addition to a content and style integrative function when the teachers are using e-textbooks in teaching. In the dimension of 'LAPI', statements on the students' needs to make marks, take notes or transmit assignments, and the parents' needs to manage their children's learning activities were found. The details of each subscale are provided in Table 3.

\section{Teachers' scores on the three perception dimensions of NUEPS}

Three subscales may be observed in Table 2, which presents the teachers' mean scores and standard deviations. The results showed that the teachers' mean scores were 4.26 to 4.40 on a five point Likert-type scale, and the standard deviations were 0.62 to 0.71 . We used multivariate analysis of variance (MANOVA) to examine whether differences existed in the perceived needs between male and female teachers in elementary and secondary schools, teachers of different ages, teachers with application experience and those without such experience.

\section{Gender difference in the perception of using e-textbooks}

To identify whether there was a significant gender difference in the needs of using e-textbooks, multivariate analysis of variance (MANOVA) was utilized (Table 4). 
Table 3 Descriptive information of the NUEPS

\begin{tabular}{|c|c|}
\hline Subscales & Description \\
\hline Function 1: Supporting teaching Activities (STA) & $\begin{array}{l}\text { When teachers are using e-textbooks in teaching, they } \\
\text { need functions to match the implementation of group } \\
\text { learning, to share group learning outputs, notes and } \\
\text { bookmarks; functions to show a fully classified booklist } \\
\text { and automatically indicate teaching progress and enable } \\
\text { access to teaching manuals and updated versions of the } \\
\text { contents at any time, and to support the exchange and } \\
\text { sharing of teaching materials; and functions for teachers } \\
\text { to provide in-class quizzes, results of formative } \\
\text { assessments, and to provide digitalized supplementary } \\
\text { teaching materials to students at any time, and functions } \\
\text { that would match with the learning diagnostic systems. }\end{array}$ \\
\hline $\begin{array}{l}\text { Function 2: Supporting features and functions } \\
\text { of Reading and Presenting (SRP) }\end{array}$ & $\begin{array}{l}\text { If teachers use e-textbooks in classroom teaching, then } \\
\text { they need functions to support page turning, show } \\
\text { the contents page, bookmarks, hypertext links, and the } \\
\text { ability to change the size, font and color of a character } \\
\text { style and hand input to facilitate reading and operations. } \\
\text { In addition, they need network access, and broadcast in } \\
\text { wireless networks to track students' reading page, provide } \\
\text { abundant content to teachers, display on various devices, } \\
\text { change contents to adapt to the teaching contents } \\
\text { consistent with learning needs, and support compatible } \\
\text { format content so that teachers can integrate their } \\
\text { teaching materials. }\end{array}$ \\
\hline $\begin{array}{l}\text { Function 3: Learning Activities and Parent } \\
\text { Interaction (LAPI) }\end{array}$ & $\begin{array}{l}\text { If teachers use e-textbooks in classroom teaching, then } \\
\text { they need functions to take notes, use the highlight } \\
\text { feature on books, enable students to batch upload } \\
\text { electronic assignments, inform parents of the use of } \\
\text { the e-textbook in class, provide a "Parent Management" } \\
\text { interface and accounts managed and used by the } \\
\text { parents that support parental reading and signing in } \\
\text { the contact books. }\end{array}$ \\
\hline
\end{tabular}

We found that gender $(F=1.863, P>0.05$; Wilks' Lambda $(\Lambda)=0.985$; partial eta squared $=0.015)$ had not reached the significant level when MANOVA was conducted at the significant level $\alpha=0.05$. The findings of this study revealed no significant difference among the 'STA', 'SRP', and 'LAPI' dimensions, suggesting that male and female teachers in Taiwan have the same perceptions regarding the use of e-textbooks in the classroom. It appears that the findings of this study are consistent with those of Liu et al. (2010), and Wang et al. (2009), who previously claimed no gender bias in teachers' use of m-learning. However, some studies have reported gender difference in their results. For example, Uzunboylu and Ozdamli (2010) found that male teachers' perceptions of m-learning technologies were comparatively more positive than those of female teachers. All Teachers have the same opportunity to join training or professional development courses about integrating technologies every semester in Taiwan.

Table 4 Descriptive statistics and F-test of gender on NUEPS dimensions

\begin{tabular}{|c|c|c|c|c|c|c|c|}
\hline & Genc & & & & $F$ value & $P$ value & Partial eta squared \\
\hline & Male & & Fem & & & & \\
\hline & $\bar{M}$ & SD & $\bar{M}$ & $\overline{S D}$ & & & \\
\hline$\overline{\text { STA }}$ & 4.24 & .689 & 4.35 & .601 & 2.650 & .104 & .007 \\
\hline SRP & 4.34 & .680 & 4.44 & .558 & 2.755 & .098 & .007 \\
\hline LAPI & 4.26 & .664 & 4.29 & .689 & .212 & .646 & .001 \\
\hline
\end{tabular}

${ }^{*} p<.05$. 
Age difference in the perception of the need to use e-textbooks

This study further analyzed the relationship between the teachers' age and the perception of using e-textbook sub-dimensions. According to the study of Hung \& Hsu (2007), the participating teachers were divided into four groups: (1) up to 30 years old, (2) between 31 and 40 years old, (3) between 41 and 50 years old, and (4) over 51 years old. The findings showed that no significant difference (Wilks' Lambda $=0.957, P>0.05$ ) existed in teachers' different age (see Table 5). The finding of this study is consistent with of Hsu et al. (2008), who claimed no age difference on the teacher's proficiency of ICT integration.

\section{Elementary and secondary school teachers' difference in using e-textbooks}

The MANOVA test showed that there were statistically significant differences in elementary and secondary school teachers in the NUEPS $(F=4.671, P<0.05$; Wilks' Lambda $(\Lambda)=0.963$; partial eta squared $=0.037$ ). In the findings shown in Table 6, a significant difference in the elementary and secondary school teachers' needs when using e-textbooks can be observed in the sub-dimension of STA. As illustrated in Table 6, elementary school teachers held statistically significant perceptions that differed from those of secondary school teachers in the sub-dimension of SRP. There were significant differences in the needs of the teachers' teaching activities, assessment and remedial learning, and students' group learning activities in STA, with the secondary school teachers having obviously fewer needs compared to the elementary school teachers. This was also true for the needs in the SRP dimension (including interface presentation and operation, network functions, teaching demonstration and information updates when elementary and secondary school teachers used e-textbooks in teaching). In the LAPI dimension (including needs for learning activities and parent management), the results of these sub-dimensions showed no significant differences, but the secondary school teachers' needs were lower than those of the elementary school teachers. These results differ from those of the survey conducted in Hong Kong, in which the results indicated that primary school teachers had no sufficient understanding or mastery of technology use in learning compared with secondary teachers (So \& Swatman, 2006). This difference could well be because Taiwanese secondary school teachers have long been revealed to face higher pressure of college entrance systems and thus seldom use technologies in the classroom.

\section{Experience difference in perceptions of using e-textbooks}

The MANOVA test showed that whether or not teachers had previously used an e-textbook made a significant difference in the NUEPS $(F=2.662, P<0.05$; Wilks'

Table 5 Results of the MANOVA and post hoc tests on age difference in the NUEPS dimensions

\begin{tabular}{|c|c|c|c|c|c|c|c|c|c|c|c|}
\hline & \multicolumn{8}{|c|}{ Age of teachers } & \multirow[t]{4}{*}{$F$} & \multirow[t]{4}{*}{$\mathbf{P}$} & \multirow[t]{4}{*}{ Post hoc } \\
\hline & $\leqq 30$ & & $31-$ & & $41-$ & & $\geqq 51$ & & & & \\
\hline & \multicolumn{2}{|c|}{$(n=50)$} & \multicolumn{2}{|c|}{$(n=187)$} & \multicolumn{2}{|c|}{$(n=121)$} & \multicolumn{2}{|c|}{$(n=14)$} & & & \\
\hline & $M$ & SD & $M$ & SD & $M$ & SD & $M$ & SD & & & \\
\hline STA & 4.14 & 0.620 & 4.30 & 0.583 & 4.35 & 0.724 & 4.45 & 0.450 & 1.539 & 0.204 & - \\
\hline SRP & 4.27 & 0.594 & 4.42 & 0.543 & 4.40 & 0.718 & 4.42 & 0.649 & 0.847 & 0.469 & - \\
\hline LAPI & 4.16 & 0.636 & 4.24 & 0.694 & 4.26 & 0.782 & 4.57 & 0.456 & 1.201 & 0.309 & - \\
\hline
\end{tabular}


Table 6 Results of the MANOVA on elementary and secondary school teachers' difference in NUEPS dimensions

\begin{tabular}{|c|c|c|c|c|c|c|c|}
\hline & \multicolumn{4}{|c|}{ Level } & \multirow[t]{3}{*}{$F$} & \multirow[t]{3}{*}{$\mathbf{P}$} & \multirow[t]{3}{*}{ Partial eta squared } \\
\hline & \multicolumn{2}{|c|}{ Secondary school } & \multicolumn{2}{|c|}{ Elementary school } & & & \\
\hline & $M$ & SD & $M$ & SD & & & \\
\hline STA & 4.16 & 0.597 & 4.35 & 0.650 & 6.876 & $0.009^{*}$ & 0.019 \\
\hline SRP & 4.29 & 0.571 & 4.43 & 0.633 & 4.236 & $0.040^{*}$ & 0.012 \\
\hline LAPI & 4.24 & 0.668 & 4.28 & 0.699 & 0.250 & 0.615 & 0.001 \\
\hline
\end{tabular}

Lambda $(\Lambda)=0.978$; partial eta squared $=0.022$ ). In the findings displayed in Table 7 , teachers with such application experience reported higher needs in 'SRF' than those without such experience. Usually, the teachers with e-textbook application experience already have a willingness to innovate using technology, and also they express more requirements regarding using e-textbooks in the classroom.

\section{Conclusion and suggestions}

\section{Research contribution}

Our research is the first study to report findings regarding teacher perceptions of e-textbooks in Taiwan. The reliability and validity of the NUEPS have been confirmed, thus providing a highly suitable scale for understanding teachers' needs when using e-textbooks. In previous k-12's studies (Chen et al., 2013; Gong et al. 2013; Taizan et al., 2012) teachers comments on e-book features and functions was not indicated. The teaching activity design (e.g., quizzes, learning to share, class cooperation) was not discussed owing to the lack of large-scale survey questionnaire tool. In this study, most of the teachers who have the experience of e-textbook in primary and secondary schools were recruited and asked to answer the questions. It showed that while implementing a mobile device in teaching the instructional design needs wireless, Classroom Response Systems and cloud computing systems. The real demands for teachers were found out. NUEPS Scale not only is good for experienced teachers, but also helps novice teachers' application of e-textbook and lesson planning. This serves as a guideline in establishing norms for the official institute, and a reference in constructing the electronic teaching system. In the meantime, in this study a e-textbook unit which integrated of new technology mobile device, wireless and cloud computing systems for school smart learning environment in the new trends of e-textbook applications was developed.

Table 7 Descriptive statistics and F test for those with or without experience on NUEPS dimensions

\begin{tabular}{|c|c|c|c|c|c|c|c|}
\hline & \multicolumn{4}{|c|}{ Level } & \multirow[t]{3}{*}{$F$ value } & \multirow[t]{3}{*}{$P$ value } & \multirow{3}{*}{$\begin{array}{l}\text { Partial eta } \\
\text { squared }\end{array}$} \\
\hline & \multicolumn{2}{|c|}{ Those with experience $(n=129)$} & \multicolumn{2}{|c|}{ Those without experience $(n=236)$} & & & \\
\hline & $M$ & SD & $M$ & SD & & & \\
\hline STA & 4.33 & .599 & 4.24 & .708 & 1.770 & .184 & .005 \\
\hline SRP & 4.44 & .580 & 4.31 & .679 & 4.112 & $.043^{*}$ & .011 \\
\hline LAPI & 4.29 & .642 & 4.26 & .773 & .177 & 674 & .000 \\
\hline
\end{tabular}




\section{Conclusion and suggestions}

For elementary and secondary school teachers in Taiwan, e-textbooks are "ones whose compilations follow the teaching objectives, contents, ability indicators and so on in the Grade 1-9 curriculum outlines, have passed review and approval, and are equipped with multimedia presenting functions plus digitalized assessing or teaching materials such as assignment and study lists" and which can be matched with mobile devices to facilitate students' ability to carry and learn at any time and place. The purpose of this study was to develop a scale of perceptions of needs of using e-textbooks (NUEPS). As a result of the four-stage development process adopted in this study, a NUEPS with 32 items was developed. To determine the factor structure, these items were examined, and regarding the assessed features, these three factors were labeled as "Supporting Teaching Activities"; "Supporting Features and Functions in Reading and Presenting", and "Learning Activities and Parent Interaction". We concluded that when using e-textbooks in teaching, teachers hold positive views (all the means of the descriptive analysis were over 4.0) on e-textbook features as well as the teachers and students' learning needs. We found that male and female teachers in Taiwan maintained no difference in opinions, but for teachers with experience using digital textbooks, their needs for "supporting reading and presenting of e-textbooks and operating functions, network access, teaching demonstration plus different format integrating functions" (SRP) were stronger compared with teachers without such experience. When elementary school teachers use e-textbooks in teaching, they have higher STA (including e-textbook's application mode, assessment and needs for remedial learning, and students' needs to share studies) and SRP needs (including supporting e-textbook presentation and operation functions, network access, teaching demonstration plus content and style integrating functions) than those of secondary school teachers. These may be related to the fact that secondary school teachers have long been exposed to higher pressure of school entrance systems and they seldom use technologies in assessments, sharing, or collaborative learning. The findings of this research revealed no significant difference between needs of using e-textbook perception of teachers and age.

The digital classroom is a new medium of instruction for both teachers and students, and is in a state of continuous innovation in Taiwan, whereby textbooks and blackboards are gradually being replaced (Chen, 2010). Many researchers have constructed e-textbook-based environments with various advanced features and functions. For example, Classroom Response Systems (CRSs) (or classroom communication systems or voting machines) are application in the educational system as they elicit more interaction between students and teachers (Salemi 2009), and help teachers to conduct formative assessments and to understand the students' prior knowledge and attitudes to facilitate their acquisition of new knowledge (Fies \& Marshall, 2006). CRSs also provide an active learning approach in the classroom (Martyn Margie, 2007). Furthermore, progress has been made in context-aware ubiquitous learning environments, which are able to sense the situation of learners and provide adaptive supports (Hwang et al. 2008).

As learning environments are changing so rapidly, an indispensable learning content in the classroom - e-textbooks, combined with mobile devices and connected to the Internet, is becoming more important for supporting learning and teaching in the classroom. E-textbooks are worth further study, as they will guide students into the next generation of learning - smart learning environments. 
Adoption of technologies lies in the hands of teachers. To bring e-textbook multimedia and m-learning features into play, it is advisable to provide customized teaching application assistance for different teacher groups when promoting the use of e-textbooks in the future, and involve the students and parents in the preparation of using such teaching application assistance in advance. Moreover, Education Bureaus and schools should provide proper training programs about independent thinking and the application of new technologies to guide in-service teachers to use e-textbooks to improve cooperative learning, interactions, etc.

Limited by time and resources this study was for teachers in three areas who attended, cannot be grouped by age and sample each course subject teachers to assign sampling, therefore, unable to explore the idea of teachers from different disciplines. One limitation is that some teachers who may understand the questionnaire described, but have no practical teaching experience with e-textbooks before. Their awareness of e-book may not be mature or sophisticated enough, which might affect the results of this study. Suggestion for future research is to enlarge the sample size. It will lead to a greater extension of exploration and discovery. Further topics regarding teachers and students' application quality surveys, application of e-textbook assessing tools, and use of multimedia contents and m-learning deserve further studies to help teachers to understand, assess and improve teaching effects.

\section{Appendix A}

\section{Interview questions for experts/teachers (outlines of interviews)}

What is your definition of e-textbooks? (Definition from the teachers' perspective).

If you use e-textbooks in classroom teaching, what type of presentation and operation interface features should e-textbooks have?

If you use e-textbooks in classroom teaching, do you think it is necessary for portable devices to have network functions?

What is your opinion on the presentation, updates and richness of the e-textbooks' contents?

If you use e-textbooks in teaching, do you need teaching activities manuals, updated versions at any time and alerts for teaching progress to match the e-textbooks?

If you use e-textbooks in teaching, do you think it is necessary to plan and support teaching management, students' learning activities and management functions or systems to help the teachers manage their classes?

Competing interests

The authors declare that they have no competing interests.

Authors' contributions

YC is the overall e-textbook project coordinator and in addition responsible for the study conception and design, acquisition of data, analysis and interpretation of data. Professor TCL and K provide comments and suggestions for this paper. All authors read and approved the final manuscript.

Author details

${ }^{1}$ Graduate Institute of Learning and Instruction, National Central University, Jhongli City, Taiwan. ${ }^{2}$ Department of Educational Psychology and Counseling, National Taiwan Normal University, Taipei City, Taiwan. ${ }^{3}$ Faculty of Science and Technology, Athabasca University, Athabasca, AB T9S 3A3, Canada. 
References

N Al-Zaidiyeen, L Mei, F Fook, Teachers' attitudes and levels of technology use in classrooms: the case of Jordan schools. Intl. Ed. Studies 3(2), 211-218 (2010)

J Bauer, J Kenton, Toward technology integration in the schools: why it isn't happening. J. Technol. Teach. Educ. 13(4), 519-546 (2005)

P Brusilovsky, G Chavan, R Farzan, Social adaptive navigation support for open corpus electronic textbooks. Adaptive Hypermedia and Adaptive Web-Based Systems 3137, 24-33 (2004)

TW Chen, How East Asian classroom may change over the next 20 years. J. Comput. Assist. Learn. 26, 28-52 (2010)

G Chen, C Gong, J Yang, X Yang, R Huang, The concept of eTextbooks in K-12 classes from the perspective of its stakeholders, in Human-computer interaction and knowledge discovery in complex, unstructured, big data (pp. 319-325), ed. by A Holzinger, G Pasi (HCl-DKK, Springer Berlin Heidelberg, 2013). Retrieved from http://link.springer.com/chapter/10.1007/978-3-642-39146-0_29

DB Daniel, WD Woody, E-textbooks at what cost? Performance and use of electronic v. print texts. Comput. Educ. $62,18-23(2013)$

MT De Jong, AG Bus, The efficacy of electronic books in fostering kindergarten children's emergent story understanding. Read. Res. Q. 39(4), 378-393 (2004)

PA Ertmer, Teacher pedagogical beliefs: the final frontier in our quest for technology integration? Educ. Technol. Res. Dev. 53(4), 25-39 (2005)

JW Everett, Cooperatively created on-line textbooks with randomly generated assignments. Journal of Online Engineering Education 1(2), Article 2 (2009)

C Fies, J Marshall, Classroom response systems: a review of the literature. J. Sci. Educ. Technol. 15(1), 101-109 (2006)

C Gong, C Chen, W Cheng, X Yang, R Huang, Presented at the 2013 IEEE 13th International Conference on Advanced Learning Technologies, in Potential Issues on Initiatively Utilizing eTextbooks in K-12 Classrooms (Beijing, China, 2013) pp. 314-318

KF Hew, T Brush, Integrating technology into K-12 teaching and learning: current knowledge gaps and recommendations for future research. Educ. Technol. Res. Dev. 55, 223-253 (2007)

$\mathrm{S}$ Hsu, Developing a scale for teacher integration of information and communication technology in grades 1-9. J. Comput. Assist. Learn. 26, 175-189 (2010)

S Hsu, PY Kuan, CH Yang, Paper presented at the Conference of International Perspectives in the Learning Sciences (ICLS) (Netherlands, Utrecht, 2008). Teacher's background and ICT uses at schools in Taiwan

YM Huang, YH Kuo, YT Lin, SC Cheng, Toward interactive mobile synchronous learning environment with contextawareness service. Comput. Educ. 51, 1205-1226 (2008)

YM Huang, YL Jeng, TC Huang, An educational mobile blogging system for supporting collaborative learning. Educational Technology \& Society 12(2), 163-175 (2009)

Y-W Hung, Y-S Hsu, Examining teachers' CBT use in the classroom: a study in secondary schools in Taiwan. Educational Technology \& Society 10(3), 233-246 (2007)

G-J Hwang, C-C Tsai, SJH Yang, Criteria, strategies and research issues of context-aware ubiquitous learning. Educational Technology \& Society 11(2), 81-91 (2008)

International Society for Technology in Education, National Education Technology Standards (NETS), 2003. Retrieved February 6, 2004, from http://cnets.iste.org/

S Järvelä, P Näykki, J Laru, T Luokkanen, Structuring and regulating collaborative learning in higher education with wireless networks and mobile tools. Educational Technology \& Society 10(4), 71-79 (2007)

SM Jung, K-B Lim, Leading Future Education: Development of Digital Textbooks in Korea (12th UNESCO-APEID International Conference Quality Innovations for Teaching and Learning, Bangkok, 2009)

J Keengwe, G Onchwari, Computer technology integration and student learning: Barriers and promise. J. Sci. Educ. Technol. 17, 560-565 (2008)

A Kodippili, D Senaratne, Is computer-generated interactive mathematics homework more effective than traditional instructor-graded homework? Br. J. Educ. Technol. 39(5), 928-932 (2008)

O Korat, A Shamir, The educational electronic book as a tool for supporting children's emergent literacy in low versus middle SES groups. Comput. Educ. 50(1), 110-124 (2008)

P Lam, J Lam, C McNaught, How usable are eBooks in an mLearning environment? International Journal of Continuing Engineering Education and Life Long Learning(IJWBC) 20(1), 6-20 (2010)

M Landoni, P Diaz, E-education: design and evaluation for teaching and learning. J. Digit. Inf. 3(4), Art 220 (2003)

T Levine, S Donitsa-Schmidt, Computer use, confidence, attitudes and knowledge: a causal analysis. Comput. Hum. Behav. 14, 125-146 (1998)

TC Liu, Teaching in a wireless learning environment: a case study. Journal of Educational Technology and Society $10,107-123(2007)$

Z Liu, X Huang, Gender differences in the online reading environment. J. Doc. 64(4), 616-626 (2008)

Y Liu, H Li, C Carlsson, Factors driving the adoption of m-learning: an empirical study. Computer \& Education 55, 1211-1219 (2010)

P Luik, J Mikk, What is important in electronic textbooks for students of different achievement level? Comput. Educ. 50, 1483-1494 (2008)

M Margie, Clickers in the classroom: an active learning approach. Educuse Quarterly 2,71-74 (2007)

S Maynard, E Cheyne, Can electronic textbooks help children to learn? Electron. Libr. 23(1), 103-115 (2005)

R McFall, E Dahm, Evalulation of a prototype of an electronic textbook application, in Proceedings of World Conference on Educational Multimedia, Hypermedia and Telecommunications (pp. 1530-1535), ed. by L Cantoni, C McLoughlin (AACE, Chesapeake, VA, 2004). Retrieved from http://www.editlib.org/p/12678. 2011.07.01

R McFall, H Dershem, D Davis, Experiences using a collaborative electronic textbook: bringing the guide on the side home with you. ACM SIGCSE Bulletin 38(1), 339-343 (2006)

MK McGowan, PR Stephens, CW Bradley, Student perceptions of electronic textbooks. Issues in Information Systems 10(2), 459-465 (2009) 
K Nelson, H Webb, Exploring student perceptions of an electronic textbook: a TAM perspective, in Proceeding of Americas Conference on Information Systems (AMCIS), 2007. Paper 107. Retrieved from http://aisel.aisnet.org/ amcis2007/107

D Nicholas, I Rowlands, HR Jamali, E-textbook use, information seeking behavior and its impact: case study business and management. J. Inf. Sci. 36(2), 263-280 (2010)

A Quan-Haase, K Martin, Seeking knowledge: an exploratory study of the role of social networks in the adoption of ebooks by historians. Proceedings of the American Society for Information Science and Technology 48, 1-10 (2011)

G Ravid, Y Kalman, S Rafaeli, Wikibooks in higher education: empowerment through online distributed collaboration. Comput. Hum. Behav. 24(5), 1913-1928 (2008)

AJ Rockinson- Szapkiw, J Courduff, K Carter, D Bennett, Electronic versus traditional print textbooks: a comparison study on the influence of university students' learning. Comput. Educ. 63, 259-266 (2013)

E Rose, The phenomenology of on-screen reading: university students' lived experience of digitised text. Br. J. Educ. Technol. 42, 515-526 (2011)

MK Salemi, Clickenomics: using a classroom response system to increase student engagement in a large enrollment principles of economics course. J. Econ. Educ. 40(4), 385-404 (2009)

JA Shepperd, JL Grace, EJ Koch, Evaluating the electronic textbook: is it time to dispense with the paper text? Teach. Psychol. 35, 2-5 (2008)

B Smith, P Caputi, P Rawstorne, Differentiating computer experience and attitudes toward computers: an empirical investigation. Comput. Hum. Behav. 16, 59-81 (2000)

T So, PMC Swatman, E-Learning Readiness of Hong Kong Teachers, 2006. Retrieved January 19, 2008Retrieved from http://citeseerx.ist.psu.edu/viewdoc/download?doi=10.1.1.65.8121\&rep=rep1\&type=pdf

J Sun, J Flores, J Tanguma, E-textbooks and students' learning experiences. Decis. Sci. J. Innov. Educ. 10, 63-77 (2012)

Y Taizan, S Bhang, H Kurokami, S Kwon, A comparison of functions and the effect of digital textbook in Japan and Korea. International Journal for Educational Media and Technology 6(1), 85-93 (2012)

T Tees, Ereaders in academic libraries: a literature review. Aust. Libr. J. 59(4), 180-186 (2010)

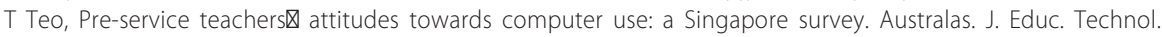
24(4), 413-424 (2008)

H Uzunboylu, F Ozdamli, Teacher perception for m-learning: scale development and teachers' perceptions. J. Comput. Assist. Learn. 27(6), 544-556 (2011)

CF Waltz, OL Strickland, ER Lenz, Measurement in Nursing and Health Research, 4th edn. (Springer Publishing Co., New York, 2010)

YS Wang, CM Wu, YH Wang, Investigating the determinants and age and gender differences in the acceptance of mobile learning. Br. J. Educ. Technol. 40, 92-118 (2009)

M Weisberg, Student attitudes and behaviors towards digital textbooks. Publishing Research Quarterly 27(2), 188-196 (2011)

JE Woodrow, The influence of programming training on the computer literacy and attitudes of preservice teachers. J. Res. Comput. Educ. 25(2), 200-218 (1992)

WD Woody, DB Daniel, CA Baker, E-books or textbooks: students prefer textbooks. Comput. Educ. 55, 945-948 (2010)

L Wozney, V Venkatesh, PC Abrami, Implementing computer technologies: teachers' perceptions and practices. J. Technol. Teach. Educ. 14(1), 173-207 (2006)

\section{Submit your manuscript to a SpringerOpen ${ }^{\circ}$} journal and benefit from:

- Convenient online submission

Rigorous peer review

- Immediate publication on acceptance

- Open access: articles freely available online

- High visibility within the field

- Retaining the copyright to your article 